\title{
Comparison of titrated oral misoprostol solution versus vaginal misoprostol for induction of labour in term obstetric patients for obstetric and neonatal outcomes: a randomized controlled trial
}

\author{
Puneeta Mahajan $^{1}$, Rajendra Popatrao Shitole ${ }^{2 *}$
}

\begin{abstract}
${ }^{1}$ Department of Obstetrics and Gynecology, Dr. Babasaheb Ambedkar Hospital, Rohini, New Delhi, India ${ }^{2}$ Department of Obstetrics and Gynecology, Dr. D. Y. Patil Medical College and Research Hospital, Pimpri, Pune, Maharashtra, India
\end{abstract}

Received: 29 March 2018

Accepted: 30 April 2018

\section{*Correspondence: \\ Dr. Rajendra Popatrao Shitole, \\ E-mail: drrajendrashitole84@gmail.com}

Copyright: (c) the author(s), publisher and licensee Medip Academy. This is an open-access article distributed under the terms of the Creative Commons Attribution Non-Commercial License, which permits unrestricted non-commercial use, distribution, and reproduction in any medium, provided the original work is properly cited.

\begin{abstract}
Background: With more than $15 \%$ of all gravid women requiring prostaglandins in cervical ripening and labour induction. However, evidence is not clear about the preferred route or dose of the drug. So this study was designed with objectives to compare the induction delivery interval and safety of titrated oral misoprostol solution with vaginal misoprostol for labour induction in term primigravida women.

Methods: In this randomised controlled trial out of 576 eligible women, 220 women as per inclusion criteria between 37 and 42 weeks of gestation with an unfavourable cervix (Bishop score <6) with indication for labour induction were randomly assigned (110each) to receive titrated oral solution of $20 \mathrm{~mL}$ misoprostol solution $(1 \mathrm{mcg} / \mathrm{mL})$ every 1 hour for four doses and then were titrated against individual uterine response or vaginal misoprostol 25 mcg every 4 hours. Vaginal delivery within 12 hours was the primary outcome. The data were analyzed by intention-to-treat.

Results: Vaginal delivery occurred within 12 hours in $56(50.9 \%)$ women in the titrated oral group and $24(21.8 \%)$ women in the vaginal group with significant p-value $(<0.001)$. The incidence of caesarean, hyper stimulation, low apgar score was less in the titrated oral group. More women experienced nausea in the titrated oral group.

Conclusions: Titrated oral misoprostol is safe and effective for labour induction in primigravida patients with unfavourable cervix.
\end{abstract}

Keywords: Apgar, Cervical ripening, Cesarean, Induction, Titrated misoprostol solution, Vaginal misoprostol

\section{INTRODUCTION}

Induction of labour is defined as the process of artificially initiating uterine contractions, prior to their spontaneous onset, with progressive effacement and dilatation of the cervix and ultimately, the delivery of the baby. ${ }^{1}$

There are many indications for term labour induction, including post dated pregnancy, preeclampsia, diabetes mellitus, oligohydramnios, intrauterine fetal growth retardation and abnormal ante partum fetal surveillance results. $^{2}$

With more than $15 \%$ of all gravid women requiring aid in cervical ripening and labour induction, there is widespread interest in, and demand for, an effective and safe method of assistance. The immature cervix is the greatest barrier to labour induction. As oxytocin affects mostly uterine contractions and minimally cervical ripening, prostaglandin agents are the first choice for labour inductions as they exert a local effect on the 
cervix, causing effacement and dilatation, and stimulate myometrial contractions, increasing the likelihood of success. $^{3}$

Dinoprostone has been the agent of choice for preinduction cervical ripening for several decades and it is currently one of the pharmacologic agents approved by the United States' Food and Drug Administration (FDA) for this purpose. ${ }^{4}$ Although widely used, it has two disadvantages: it is expensive, and it requires continuous refrigeration. Thus, there is a need for less costly and less temperature-sensitive alternatives. A proposed alternative is misoprostol, a synthetic prostaglandin E1 analogue. Misoprostol, initially used to treat peptic ulcers caused by prostaglandin synthetase inhibitors, was approved by the FDA for obstetric use in April 2002.

Since 1992 as published in the article of Margulies et al and the initial American clinical report by SanchezRamos et al, detailing the use of misoprostol for cervical ripening and labour induction, there has been growing interest in this agent. ${ }^{5-8}$ The preferred dosage is $50 \mu \mathrm{g}$ orally or $25 \mu \mathrm{g}$ vaginally every 4 hours. However, excessive uterine contractility resulting in fetal distress is a cause for concern. ${ }^{9-14}$ Comparing the oral and vaginal administrations of misoprostol, oral administration is easier and has greater acceptability among women. Further, absorption is more rapid and possibly more predictable, with a peak serum concentration following oral administration of 34 minutes and a half-life of 20-40 minutes. Peak serum concentration for vaginal administration is 60-80 minutes, this level being sustained for up to 4 hours. ${ }^{15}$

Although the direct local effect of vaginal administration on cervical ripening may be advantageous, the shorter half-life of oral delivery may be beneficial in the event of uterine hyper stimulation. ${ }^{16-18}$

In order to avoid uterine hyper stimulation, it appears reasonable to suggest that oral misoprostol should be administered in small, frequent doses, titrated against the uterine response. ${ }^{19}$

Primary objectives were to compare induction delivery intervals by oral titrated misoprostol solution and vaginal misoprostol in term primigravida women requiring induction of labour and to compare Vaginal delivery rate within $12 \mathrm{hrs}$.

\section{Secondary objectives were:}

- Induction failure (inability to achieve active phase of labour despite an adequate stimulation that lasted atleast $6 \mathrm{hrs}$ after amniotomy or not entering into active phase after $36 \mathrm{hrs}$ of misoprostol treatment).

- Vaginal delivery between 12-24hrs

- Complications

i. Tachysystole/ hypertonous/ hyperstimulation ii. Neonatal complications like meconium stained liquor, low apgar score and admission to neonatal unit

iii. Maternal side effects like nausea, diarrhea, shivering and pyrexia.

\section{METHODS}

This randomized controlled trial was conducted in the department of obstetrics and gynecology at Sanjay Gandhi Memorial Hospital, Mangolpuri, Delhi during the period of $1^{\text {st }}$ April 2012 to $30^{\text {th }}$ April 2013.

This hospital is an approximately 150 bedded maternity hospital which caters the north-west population of delhi which mainly includes lower socio- economic strata. The hospital serves all (booked/unbooked/referred/high risk) Obstetric cases with delivery rate of approximately 7000/year.

Two groups were made:

1. Intervention group (group I): This group received titrated oral misoprostol solution (prepared a1 tablet of 200 microgram dissolved in $200 \mathrm{ml}$ of drinking water used as $20 \mathrm{ml} / \mathrm{hr}$ ).

2. Control group (group II): This group received conventional vagina misoprostol 25 microgram 4 hrly which was the standard clinical practice used for induction of labour in our set up.

The sample size calculation was based on $25 \%$ of the incidence of the primary outcome which was vaginal delivery within 12 hours, as previously reported in pilot study of labour induction with titrated oral misoprostol. Detection of an increase to $50 \%$ with $95 \%$ certainty and $90 \%$ power with an additional $20 \%$ sample size for potential loss of control group subjects during the labour course was estimated to require 110 women in each group.

Approval from institutional ethical committee was sought and obtained before instituting the study.

A written informed consent was taken from the eligible subjects regarding willingness to participate in the study.

The eligible population was all primigravida patients with gestational age between 37-42 weeks admitted for induction of labour with bishop score $<6$ and normal admission CTG. Patients with Any contraindication for induction with misoprostol like Foetal distress, Previous uterine surgery, Hypersensitivity to misoprostol ,Significant maternal cardiac, renal, respiratory or hepatic disease, Refused for consent, Patients in active labour(dilation $>4 \mathrm{~cm}$ )/bishop score $>6$, Abnormal admission CTG were excluded.

\section{Randomization}


- Sequence generation: Randomisation of enrolled subjects to either group was done by Statistician through computer generated random number sequence. No block randomization was done.

- Allocation concealment: Allocation concealment was done through SNOSE (Serially Numbered Opaque Sealed Envelopes). This was concealed from the primary investigator (myself) enrolling and assessing participants.

- Implementation of intervention: Each enrolled subject after obtaining written informed consent given serially numbered envelope for the treatment.

This study was not blinded as two forms of therapy were obvious and both women and clinician were aware of the allocated treatment.

\section{Implementation of protocol}

Misoprostol is available as an oral tablet and is watersoluble. The uterine activity produced by an oral solution is faster and stronger than that of an oral tablet, or when given by the rectal or vaginal route. One tablet of misoprostol is of $200 \mathrm{mcg}$.

\section{Implementation in intervention group}

In this study, a tablet was dissolved in $200 \mathrm{~mL}$ drinking water in a normal saline bottle. The misoprostol solution was used completely within 24 hours after preparation or discarded. Women assigned to the titrated oral route were induced with a basal unit of $20 \mathrm{~mL}$ misoprostol solution $(1 \mathrm{mcg} / \mathrm{mL})$ prepared as described above.

The administration procedure followed these guidelines

- Initial administration of $20 \mathrm{mcg}$ per hour was undertaken until adequate uterine contractions were achieved. When contractions do not occur after four of the above doses, the dosage were increased to 40 mcg ,60 mcg and repeated every hour until uterine contractions were achieved, with a maximum of four more doses.

- Once uterine activity was deemed adequate, no further misoprostol was given.

- When contractions subsequently became inadequate, hourly doses of misoprostol solution were started at $10 \mathrm{mcg}$ and increased to $20 \mathrm{mcg}$ and perhaps $40 \mathrm{mcg}$ based on uterine responsiveness. This process was repeated until adequate uterine contractions occurred.

\section{Implementation in control group}

Women assigned to the vaginal misoprostol group received $25 \mathrm{mcg}$ every 4 hours until attaining a more favourable cervix (Bishop score greater than or equal to 6 ) or adequate uterine activity (greater than or equal to three contractions in 10 minutes) or entering active labour.
The procedural guidelines common to the administration of misoprostol by the vaginal route or the titrated oral route were as follows:

- Fetal heart rate and uterine activity were monitored throughout labour induction by stethoscope intermittently and CTG 4hrly.

- Induction failure was defined as not entering into the active phase after 36 hours of misoprostol treatment with a maximal cumulative dosage of $1,600 \mathrm{mcg}$.

- Intravenous magnesium sulfate (4 g during 30 minutes) was given at obstetrician's discretion when uterine hyperstimulation occured.

- When rupture of membranes did not occur despite a Bishop's score of 9 or above, artificial rupture of the membrane was performed at obstetrician's discretion.

- Supplemental oxytocin was used at obstetrician's discretion when uterine contractions were inadequate when entering into the active phase because of poor response to misoprostol.

- Caesarean delivery was offered to all patients after induction failure or a prolonged active phase.

Adequate uterine contractions in this study were defined as occurring every 2-3 minutes and lasting 60-90 seconds, with an intrauterine pressure $50-60 \mathrm{~mm} \mathrm{Hg}$. Tachysystole was defined as the presence of at least six contractions in 10 minutes over at least two 10-minute windows.

Hyper tonus was defined as a single contraction lasting more than 2 minutes. Hyper stimulation was defined as tachysystole or hyper tonus with non-reassuring FHR changes.

Fetal heart rate changes considered to be non-reassuring were late deceleration, severe variable deceleration, prolonged deceleration, tachycardia, or reduced FHR variability requiring intervention either by tocolytics or delivery. All these parameters were confirmed with CTG and senior obstetrician.

\section{On-going monitoring and assessment of outcome}

\section{Monitoring}

- $\quad$ FHR- $1 / 2$ hrly or as required*

- $\quad$ CTG- 4 hrly or as required*

- PV examination- was done by same person whenever required. For quality control random confirmation of these findings were done by senior consultant.

- Fetal heart rate changes which required frequent monitoring like late deceleration, severe variable deceleration, prolonged deceleration, tachycardia, or reduced FHR variability requiring intervention either by tocolytics or delivery or suspicion of tachysystole/hypertonus/hyperstimulation on clinical examination. 
Table 1: Bishop score.

\begin{tabular}{|llllll|}
\hline Score & $\begin{array}{l}\text { Cervical } \\
\text { dilatation }\end{array}$ & $\begin{array}{l}\text { Cervical } \\
\text { effacement }\end{array}$ & Station of baby & $\begin{array}{l}\text { Cervical } \\
\text { position }\end{array}$ & $\begin{array}{l}\text { Cervical } \\
\text { consistency }\end{array}$ \\
\hline 0 & $<1 \mathrm{~cm}$ & $0-30 \%$ & -3 & Posterior & Firm \\
\hline 1 & $1-2 \mathrm{~cm}$ & $40-50 \%$ & -2 & Mid; anterior & Average \\
\hline 2 & $2-4 \mathrm{~cm}$ & $60-70 \%$ & $-1 / 0$ & & Soft \\
\hline 3 & $>4 \mathrm{~cm}$ & $80 \%$ & $+1 /+2$ & & \\
\hline
\end{tabular}

\section{Data collection}

A pre structured performa was used to obtain history taking, clinical examination, investigations, progress of labour, outcomes of labour.

The defined primary and secondary outcomes were measured and documented.

\section{Statistical analysis}

Data was recorded in a pre-designed Performa and managed on an excel spread sheet.

Statistical analyses were performed using the SPSS version 17.0 program for Windows. Authors conducted a Shaipro Wilk test to verify the distribution of the data. All data were summarized as the mean $\pm \mathrm{SD}$, while those with a skewed distribution were described as a median (IQR). The chi-square test was used to compare the differences in variᄀables between the two groups. Student's t-test was used for continuous, normal variables. The Mann-Whitney test was used to test independent relationships between the variables that did not demonstrate normality. A two-sided $\mathrm{P}$ value less than 0.05 was considered statistically significant.

\section{RESULTS}

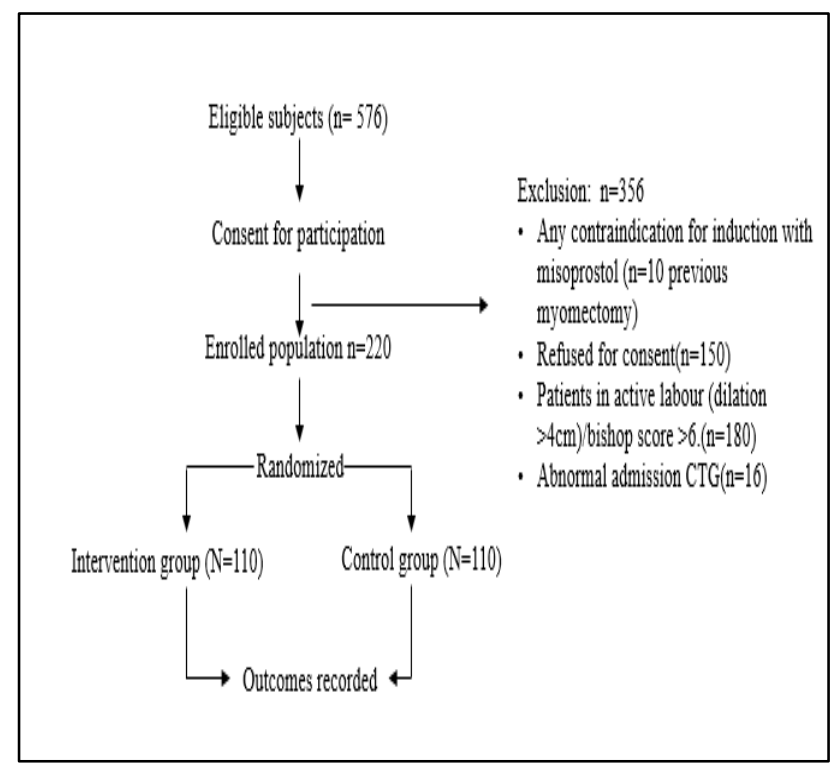

Figure 1: Study flow chart.

None of the women from either group withdrew from the study.

Table 2: Indications for induction of labour.

\begin{tabular}{|lllll|}
\hline Indication for induction & Study group & & Control group & P Value \\
\hline IUGR & Frequency & Percentage & Frequency & Percentage \\
\hline PROM & 9 & 8.2 & 9 & 8.2 \\
\hline Post Dated & 20 & 18.2 & 16 & 14.5 \\
\hline Rh-negative & 56 & 50.9 & 54 & 49.1 \\
\hline Hypertension & 0 & 0.0 & 3 & 2.7 \\
\hline Oligo-hydramnios & 21 & 19.1 & 24 & 21.8 \\
\hline Others & 0 & 0.0 & 4 & 3.6 \\
\hline Total & 4 & 3.6 & 0 & 0.0 \\
\hline
\end{tabular}

Distribution of indications for induction of labour was similar in both the groups with $\mathrm{P}=0.069$.
The median total dosage was $120 \mathrm{mcg}$ in the titrated oral group and $75 \mathrm{mcg}$ in the vaginal group (P-value $<0.001)$. 
Table 3: Total dosage of misoprostol required.

\begin{tabular}{|llllll|} 
& \multicolumn{2}{l}{ Study group $(\mathrm{n}=110)$} & \multicolumn{2}{c|}{ Control group $(\mathrm{n}=110)$} & \\
& Median & IQR & Median & IQR & P Value \\
\hline Total dosage & 120 & $60-160$ & 75 & $50-100$ & $<0.001$ \\
\hline
\end{tabular}

Table 4: Vaginal delivery within 12 hrs and 12-24 hrs.

\begin{tabular}{|llllll|}
\hline Vaginal delivery & Study group & & \multicolumn{2}{l|}{ Control group } & \multicolumn{2}{c|}{ P Value } \\
\hline & Frequency & Percentage & Frequency & Percentage & $<0.001$ \\
\hline$<12 \mathrm{hrs}$ & 56 & 50.9 & 24 & 21.8 & 0.061 \\
\hline $12-24 \mathrm{hrs}$ & 46 & 50.6 & 57 & 62.7 & 0.7 \\
\hline
\end{tabular}

Table 5: Induction to delivery interval (IDI).

\begin{tabular}{|c|c|c|c|c|c|}
\hline & \multicolumn{2}{|c|}{$\begin{array}{l}\text { Study Group } \\
(\mathrm{n}=110)\end{array}$} & \multicolumn{2}{|c|}{$\begin{array}{l}\text { Control Group } \\
(n=110)\end{array}$} & \multirow{2}{*}{$\begin{array}{l}\mathbf{P} \\
\text { Value }\end{array}$} \\
\hline & Median & IQR & Median & IQR & \\
\hline $\begin{array}{l}\text { Induction } \\
\text { to active } \\
\text { phase } \\
\text { interval } \\
\text { (hrs) }\end{array}$ & 7.00 & $\begin{array}{l}4.00 \\
- \\
10.20\end{array}$ & 10.00 & $\begin{array}{l}8.00 \\
- \\
13.00\end{array}$ & $<0.001$ \\
\hline $\begin{array}{l}\text { Induction } \\
\text { delivery } \\
\text { interval } \\
\text { (hrs) }\end{array}$ & 11.5 & $\begin{array}{l}10.17 \\
- \\
18.10\end{array}$ & 15.05 & $\begin{array}{l}12.00 \\
- \\
24.10\end{array}$ & 0.001 \\
\hline
\end{tabular}

There were significantly more women who delivered vaginally within 12 hours $(50.9 \%$ as compared to $21.8 \%$ with p-value of <0.001). In 12-24 hours women who delivered vaginally were $50.6 \%$ in the titrated oral group as compared to $62.7 \%$ in the vaginal group with insignificant p-value of 0.061 .

The median interval from the first dose of misoprostol to vaginal delivery was 11.5 hours in the titrated oral group and 15.05 hours in the vaginal group ( $\mathrm{P}$-value 0.001$)$.

Percentage of women who had normal delivery in Group I was $85.5 \%$ and Group II $70.9 \%$, instrumental delivery nil in Group I and Group II 5.4\%, LSCS in Group I $14.5 \%$ and in Group II $23.6 \%$, with $\mathrm{P}=0.020$. This difference is statistically significant.

Table 6: Mode of delivery.

\begin{tabular}{|llllll|}
\hline Mode of delivery & Study group & & Control group & & P Value \\
\hline c-section & Frequency & Percentage & Frequency & Percentage & 0.020 \\
\hline Normal & 16 & 14.5 & 26 & 23.6 & 70.9 \\
\hline Forceps & 94 & 85.5 & 78 & 2.7 \\
\hline Vacuum & 0 & 0.0 & 3 & 2.7 \\
\hline Total & 0 & 0.0 & 3 & 100 \\
\hline
\end{tabular}

Table 7: Maternal complications.

\begin{tabular}{|llllll|}
\hline Maternal complications & Study group & & \multicolumn{2}{c|}{ Control group } & \multicolumn{2}{c|}{ P value } \\
\hline Hyperstimulation & Frequency & Percentage & Frequency & Percentage \\
\hline Nausea & 1 & 0.9 & 6 & 5.5 & 0.119 \\
\hline Pyrexia & 17 & 15.5 & 0 & 0.0 & $<0.001$ \\
\hline Shivering & 2 & 1.8 & 3 & 2.7 & 1.000 \\
\hline Tachsystole & 3 & 2.7 & 1 & 0.9 & 0.622 \\
\hline Vomiting & 5 & 4.5 & 7 & 6.4 & 0.768 \\
\hline
\end{tabular}

No patient in the group II (vaginal) experienced nausea, vomiting, whereas in group I (the titrated oral group) nausea occurred in $17(15.5 \%)$ women, vomiting in 8 $(7.3 \%)$ with significant $p$-value. Whereas incidence of 
hyperstimulation (5.5\%) and tachysystole (6.4\%) was higher in group II than group I.

\section{DISCUSSION}

Multiple trials have shown that misoprostol is an effective agent for cervical ripening and labor induction. Vaginal as well as oral misoprostol administration has been used, with 25 mcg every 4 hours widely accepted as the most effective regimen with the least number of complications. But there are limited studies on titrated oral misoprostol solution in the literature.

This randomised controlled trial was undertaken to compare the efficacy and safety of a novel dosing regimen of titrated oral misoprostol with the standard regiment of vaginal misoprostol every 4 hours. Uterine hyper stimulation is always a concern in either regular or stepwise administration of oral/vaginal misoprostol every 4hours. To avoid uterine hyper stimulation and shorten the interval from induction to vaginal delivery, we adopted the principle that misoprostol should be administered orally in small, frequent doses (one dose per hour generally), titrated against uterine response and analogous to the conventional titrated use of oxytocin. This method is easier to administer than vaginal suppositories and is less expensive than intravenous oxytocin administered by an infusion pump. There was no statistically significant difference in both groups in age in years as well as gestational age in weeks.

Most of the indications for induction were similar between the two groups with $\mathrm{P}=0.069$. Most common indication for induction in both the groups was post-dated pregnancy followed by hypertension in pregnancy. In PROM group, in vaginal misoprostol group high leak was present and leaking was minimal so tablets were used vaginally.

Mean Bishop Score was not statistically different in the two groups $(\mathrm{P}=0.224)$. Mean bishop score in Group I was $3.35 \pm 0.91$ and in Group II it was 3.10 \pm 1.00 .

The median total dosage was $120 \mathrm{mcg}$ in the titrated oral group and $75 \mathrm{mcg}$ in the vaginal group $(P$-value $<0.001)$. Although the total dosage of titrated oral misoprostol ranged from $60 \mathrm{mcg}$ to $160 \mathrm{mcg}$, only $18.2 \%$ (20 of 110) of patients in the titrated oral misoprostol group needed oxytocin augmentation, which was a far lower percentage than the $39.1 \%$ (43 of 110) in the vaginal misoprostol group.

The study by Kwon et al showed similar results, mean number of doses and total dose required was more in oral group as compared to the vaginal group.

This is attributed to pharmacokinetics of misoprostol which is different for each route. For oral administration, the onset of action is 8 minutes, Tmax is 30 minutes and duration of action is 2 hours. For vaginal administration, the onset of action is 20 minutes, Tmax is 70 minutes and duration of action is 4 hours, hence vaginal misoprostol remains effective for longer time and hence lesser dosage is required for induction of labour.

Cheng S study showed, only $10.9 \%$ (11 of 101) of patients in the titrated oral misoprostol group needed oxytocin augmentation, which was a far lower percentage than the $53.8 \%$ (57 of 106) in the vaginal misoprostol group (RR 0.11, 95\% CI 0.05-0.22). ${ }^{3}$

The mean induction to delivery interval in this study was found to be 11.5 hours in Group I and in Group II mean was 15.05 hours with significant p-value of 0.001 .

There were significantly more women who delivered vaginally within 12 hours in the titrated oral group than in the vaginal group $50.9 \%$ compared with $21.8 \%$ with significant $\mathrm{p}$-value of $<0.001$. In $12-24$ hours women who delivered vaginally were $50.6 \%$ in the titrated oral group as compared to $62.7 \%$ in the vaginal group with insignificant p-value of 0.061 . Thus, significantly more women delivered within $12 \mathrm{hrs}$ in titrated oral misoprostol group.

Cheng S study showed the median interval from the first dose of misoprostol to vaginal delivery was 8.2 hours in the titrated oral group and 17.6 hours in the vaginal group (P-value 0.01). ${ }^{3}$ Vaginal delivery occurred within 12 hours in $75(74.3 \%)$ women in the titrated oral group and $27(25.5 \%)$ women in the vaginal group (relative risk (RR) $8.44,95 \%$ confidence interval (CI) 4.52-15.76).

Aalami-Harandi $\mathrm{R}$ et al study also showed that in comparison with the oxytocin group, patients in the titrated oral misoprostol group had significantly higher rate of vaginal deliveries at time intervals of 18 and 24 hours during the study period $(67.1,79.7 \%$ versus 53.1 , $61.7 \%$ respectively; all p-values were $<0.05){ }^{20}$

Number of patients who had normal vaginal delivery was, $94(85.5 \%)$ in Group I compared to 78 (70.9\%) in Group II, 6 patients from Group II had instrumental delivery in view of prolonged $2^{\text {nd }}$ stage of labour. 16 (14.5\%) from Group I and 26 (23.6\%) from Group II underwent emergency caesarean section. Indications for caesarean section in Group I was 9 cases in view of fetal distress, 3 cases in view of failed induction and 4 cases in view of failure to progress. Indications for 16 cases in Group II was fetal distress, 6 cases in view of failed induction, 2 cases in view of deep transverse arrest and 2 cases for failure to progress. The mode of delivery in terms of normal vaginal, instrumental (forceps/vacuum) and LSCS was significant in group I with p-value of 0.020 .

Shi-Yann Cheng ${ }^{3}$ study showed, Eighteen (17.0\%) patients in the vaginal group underwent caesarean delivery compared with only four $(4.0 \%)$ patients in the titrated oral group (RR $0.20,95 \%$ CI $0.07-0.62$ ) with 
significant $\mathrm{p}$-value of $<0.01$. There were no differences in the modes of delivery in the study reported by Shetty Ashalatha. $^{21}$

Aalami-Harandi $\mathrm{R}$ et al study results showed higher rate of vaginal deliveries in women undergoing labour induction with titrated oral misoprostol compared with oxytocin $(79.7$ versus $61.7 \%){ }^{20}$ The caesarean section rate, latent period and period from induction to vaginal delivery were significantly lower for the misoprostol group.

Wing DA et al also showed that more orally treated women delivered vaginally in 24 hours than vaginally treated women ( 74 versus $54, \mathrm{P}=.14$, relative risk [RR] $1.14,95 \%$ confidence interval [CI ]0.92, 1.40). ${ }^{9}$

In the present study, incidence of meconium coloured liquor from both the groups was comparable (10[9.1\%] in group I compared to $16[14.5 \%]$ in II) with insignificant p-value of 0.210 .4 neonates out of these required NICU admission in group I as compared to 10 neonates in group II. All pts in group I required caesarean section and 14 pts in group II. Two pts in group II delivered vaginally.

Ashalatha S study showed meconium in oral group 19 $(13.4 \%)$ and in vaginal group16 (12.2\%), Rasheed R et al, study showed meconium in $39(12.5 \%)$ patients (19 $(11.51 \%)$ in oral group and $20(13.79 \%)$ in the vaginal group $(\mathrm{p}<0.52)) .{ }^{21,22}$ Shi-Yann Cheng study showed there were no differences in neonatal outcomes. AalamiHarandi $\mathrm{R}$ et al study results showed one patient $(0.7 \%)$ in oxytocin group and none of the subjects in misoprostol group had meconium in amniotic fluid $(\mathrm{p}=1.0) .^{20}$

1 minute APGAR $<7$ was seen in 29 neonates in groups I and 25 neonates In Group II. 6 babies' In Group I and 11 in group II were admitted to NICU in view of respiratory distress syndrome. 4 neonates in group I and 9 in group II had APGAR score $<7$ at 5 minutes.

Cheng S study showed, there were no differences in neonatal outcomes except for fewer patients with APGAR scores less than 7 at 1 minute in the titrated oral group. ${ }^{3}$ However, it was noted that the labour course of induction was more than 24 hours in five of six newborns with Apgar scores less than 7 at 5 minutes in the vaginal group. Aalami-Harandi $\mathrm{R}$ et al study results showed that 1 and 5-Minute Apgar scores and birth weight were similar between the two groups $(\mathrm{p}=0.05) .{ }^{20}$ Admission in neonatal intensive care unit was seen more frequently in oxytocin group $(3.9 \%)$ than in misoprostol group $(0.7 \%)$; however, this difference was not statistically significant $(\mathrm{p}=0.02)$.

In the present study, only one case from Group I developed hyperstimulation $(0.9 \%)$ as compared to 6 cases in group II, this difference was not statistically significant. Cases which developed hyperstimulation, were given injection magnesium sulphate as per protocol.
1 case in group I and 3 cases in group II required caesarean section for fetal distress due to hyperstimulation. Out of 3 remaining cases in group II, 1 required LSCS for DTA, 1 delivered vaginally, 1 required forcep application. Other side effects like tachysytole, pyrexia, shivering were similar in both the groups except nausea and vomiting which were significantly higher in group I. Tachysystole incidence was similar in both the groups but further doses of misoprostol immediately halted in group I as it was titrated against contractions \& that prevented further hyperstimulation. Then, a small dosage of misoprostol was added to augment uterine contractions.

Cheng S study showed, treatment adverse effects were similar in the two groups except that no patient in the vaginal group experienced nausea, vomiting, and diarrhea, whereas in the titrated oral group nausea occurred in $11(10.9 \%)$ women, vomiting in nine $(8.9 \%)$, and diarrhea in five $(5.0 \%) .^{3}$

Aalami-Harandi $\mathrm{R}$ et al study results showed that gastrointestinal symptoms were observed more frequently in the misoprostol than in the oxytocin group (10.9 versus $3.9 \%, \mathrm{p}=0.03)$; all of them were treated conservatively. ${ }^{20}$

\section{CONCLUSION}

Titrated oral misoprostol is associated with a higher delivery rate within $12 \mathrm{hrs}$ as compared to vaginal misoprostol. Titrated oral misoprostol is also associated with lower incidence of uterine hyperstimulation and a lower cesarean delivery rate than vaginal misoprostol for labour induction in patients with unfavourable cervix. Number of doses of misoprostol used in vaginal route of administration, was significantly lesser compared to oral route. Lesser number of patients in titrated oral misoprostol group required oxytocin augmentation as compared to vaginal misoprostol group. Gastrointestinal side effects were higher in oral group. There was no significant difference in fetal complications in both groups.

\section{Funding: No funding sources}

Conflict of interest: None declared

Ethical approval: The study was approved by the Institutional Ethics Committee

\section{REFERENCES}

1. Martin JA, Hamilton BE, Sutton PD ET (2005): AL Births: final data for 2003: National vital statistics Reports: 54 (2).Hyattsville, MD:National center for Health Statistics.

2. American College of Obstetricians and Gynecologists, Committee on Obstetrics. Induction of labour. ACOG Technical Bulletin 217. Washington (DC): ACOG;1995.

3. Shi-Yann Cheng, MD, Ho Ming, MD, and Jui-Chi Lee, MD. Titrated oral compared with vaginal 
misoprostol for labour induction. Obstet Gynecol 2008;111:119-25.

4. Kelly AJ, Kavanagh, Thomas J. vaginal PGE2 gel for induction of labour at term, Cochrane database systemic review2003(4):CD003101.

5. Sanchez-Ramos L, Kaunitz AM, Del Valle GO, Delke I, Schroeder PA, Briones DK. Labour induction with prostaglandin E1 methyl analogue misoprostol versus oxytocin: a randomized trial. Obstet Gynecol 1993;81:332-6.

6. Hofmeyr GJ, Gulmezoglu AM, Alfirevic Z. Misoprostol for the induction of labour: a systemic review. Br J Obstet Gynecol. 1999;106:798-803.

7. Wing DA. Labour induction with misoprostol. Am J Obstet Gynecol. 1999;180:339-45.

8. Keirse MJNC. Prostaglandins in preinduction cervical ripening. Meta-analysis of worldwide clinical experience. J Reprod Med. 1993;38 suppl:89-98.

9. Wing DA, Park MR, Paul RH. A randomized comparison of oral and intravaginal misoprostol for labour induction. Obstet Gynecol. 2000;95:905-8.

10. Alfirevic Z, Weeks A. Oral misoprostol for induction of labour. Cochrane Database Sys Rev. 2006;(2):CD001338.

11. Weeks A, Alfirevic Z. Oral misoprostol administration for labour induction. Clin Obstet Gynecol. 2006;49:658-71.

12. Wing DA, Gaffaney CA. Vaginal misoprostol administration for cervical ripening and labour induction. Clin Obstet Gynecol. 2006;49:627-41.

13. Hofmeyr GJ, Gulmezoglu AM. Vaginal misoprostol for cervical ripening and labour induction in late pregnancy (Cochrane Review). In: The Cochrane Library, Issue 2, 2001. Oxford: Update Software.

14. Alfirevic Z, Howarth G, Gausmann A. Oral misoprostol for induction of labour with a viable fetus (Cochrane Review). In: The Cochrane Library, Issue 2, 2001. Oxford: Update Software.

15. Zieman M, Fong SK, Benowitz NL, Banskter D, Darney PD. Absorption kinetics of misoprostol with oral or vaginal administration. Obstet Gynecol. 1997;90:88-92.

16. Bennett KA, Butt K, Crane JM, Hutchens D, Young DC. A masked randomized comparison of oral and vaginal administration of misoprostol for labour induction. Obstet Gynecol. 1998;92:481-6.

17. Wing DA, Ham D, Paul RH. A comparison of orally administered misoprostol with vaginally administered misoprostol for cervical ripening and labour induction. Am J Obstet Gynecol. 1999; 180:1155-60.

18. Shetty A, Martin R, Danielian P, Templeton A. A comparison of two dosage regimens of oral misoprostol for labour induction at term. Acta Obstet Gynecol Scand. 2002;81:337-42.

19. Danielsson KG, Marions L, Rodriguez A, Spur BW, Wong PY, Bygdeman M. Comparison between oral and vaginal administration of misoprostol on uterine contractility. Obstet Gynecol. 1999;93:275-80.

20. Aalami-Harandi R, Karamali M, Moeini A. Induction of labor with titrated oral misoprostol solution versus oxytocin in term pregnancy: randomized controlled trial. Rev Bras Gyanecol Obstet. 2013;35(2):60-5

21. Ashalatha Shetty, Peter Danielian, Allan Templeton. A comparison of oral and vaginal misoprostol tablets in induction of labour at term. Br J Obstet Gynaecol. 2001;108:238-243.

22. Rasheed R, Alam AA, Younus S, Raza F. Oral versus vaginal Misoprostol for labour induction. J Pak Med Assoc. 2007;57(8):404-7.

Cite this article as: Mahajan P, Shitole RP. Comparison of titrated oral misoprostol solution versus vaginal misoprostol for induction of labour in term obstetric patients for obstetric and neonatal outcomes: a randomized controlled trial. Int J Reprod Contracept Obstet Gynecol 2018;7:2339-46. 